\title{
Neurobehavioural Changes and Brain Oxidative Stress Induced by Acute Exposure to GSM900 Mobile Phone Radiations in Zebrafish (Danio rerio)
}

\author{
Abhijit Nirwane, Vinay Sridhar and Anuradha Majumdar \\ Department of Pharmacology, Bombay College of Pharmacy, Kalina, Mumbai, India
}

(Received April 27, 2015; Revised September 8, 2015; Accepted November 25, 2015)

\begin{abstract}
The impact of mobile phone (MP) radiation on the brain is of specific interest to the scientific community and warrants investigations, as MP is held close to the head. Studies on humans and rodents revealed hazards MP radiation associated such as brain tumors, impairment in cognition, hearing etc. Melatonin (MT) is an important modulator of CNS functioning and is a neural antioxidant hormone. Zebrafish has emerged as a popular model organism for CNS studies. Herein, we evaluated the impact of GSM900MP (GSM900MP) radiation exposure daily for $1 \mathrm{hr}$ for 14 days with the SAR of $1.34 \mathrm{~W} / \mathrm{Kg}$ on neurobehavioral and oxidative stress parameters in zebrafish. Our study revealed that, GSM900MP radiation exposure, significantly decreased time spent near social stimulus zone and increased total distance travelled, in social interaction test. In the novel tank dive test, the GSM900MP radiation exposure elicited anxiety as revealed by significantly increased time spent in bottom half; freezing bouts and duration and decreased distance travelled, average velocity, and number of entries to upper half of the tank. Exposed zebrafish spent less time in the novel arm of the Y-Maze, corroborating significant impairment in learning as compared to the control group. Exposure decreased superoxide dismutase (SOD), catalase (CAT) activities whereas, increased levels of reduced glutathione (GSH) and lipid peroxidation (LPO) was encountered showing compromised antioxidant defense. Treatment with MT significantly reversed the above neurobehavioral and oxidative derangements induced by GSM900MP radiation exposure. This study traced GSM900MP radiation exposure induced neurobehavioral aberrations and alterations in brain oxidative status. Furthermore, MT proved to be a promising therapeutic candidate in ameliorating such outcomes in zebrafish.
\end{abstract}

Key words: GSM900, Mobile phone, Cognition, Zebrafish, Specific Absorption Rate (SAR), Melatonin

\section{INTRODUCTION}

Cell phone technology has revolutionized the telecommunication scenario (1) and cell phone has grown exponentially in the last decade (2). This omnipresence and exponential growth of personal telecommunication devices like global system for mobile communication (GSM) cell phone and radiation emitted by them has become an issue of debate concerning the associated health risk (3). A cell phone transmits 1 to 2 Watt of power in the frequency range of

Correspondence to: Anuradha Majumdar, Department of Pharmacology, Bombay College of Pharmacy, Kalina, Mumbai, India 400098

E-mail: anuradha.majumdar@gmail.com

This is an Open-Access article distributed under the terms of the Creative Commons Attribution Non-Commercial License (http:// creativecommons.org/licenses/by-nc/3.0) which permits unrestricted non-commercial use, distribution, and reproduction in any medium, provided the original work is properly cited.
824 849 MHz (CDMA), 890 915 MHz (GSM900), 1710 $1780 \mathrm{MHz}$ (GSM1800), and 2110 2170 MHz for 3G (2). Every cell phone has a SAR (Specific Absorption Rate) rating, which is the rate at which radio frequency energy is absorbed in the human body over a given time and expressed as Watts $/ \mathrm{Kg}$. The International Commission on Non Ionizing Radiation Protection (ICNIRP) and Institute of Electrical and Electronics Engineers (IEEE) has laid down certain limits of mobile phone radiation exposure (4). In USA and Europe, maximum SAR limit for mobile phone is $1.6 \mathrm{~W} / \mathrm{Kg}$ and $2.0 \mathrm{~W} / \mathrm{Kg}$, respectively for 6 mins daily usage. This fall under the safety margin between 3 to 4 , which restricts mobile phone usage for not more than 18 to 24 mins per day. Above technicalities are always overlooked by the users, so millions of people use cell phones crossing the specified limit without realizing its possible health risk (2).

There is several health hazards associated with cell phones radiations (5). One amongst them is the thermal effects of these radiations that lead to localized increase in tissue tem- 
perature, which may cause disruption of cell function. The extent of heating depends on SAR and power density of electromagnetic waves (6). Non-thermal effects of mobile phone radiation amass over time and the menaces are more evident after 8 to 10 years of exposure (7) as in the initial years of exposure body's defense mechanisms and the stress proteins, specifically the heat shock proteins come into play (8). Mobile phones are kept near the head during talking mode thus it is in close proximity to the brain. Making it imperative to thoroughly investigate its impact on central nervous system (CNS). Exposure to electromagnetic radiations has shown to be associated with Alzheimer's disease, Motor neuron disease and Parkinson's disease (9), Seizures, Paralysis, Psychosis and Stroke (10). Nittby et al. in 2008 reported significant memory impairment in rats after long term exposure to GSM900 mobile phone radiation (11). In yet another study, mobile phone exposure (GSM900/1800) affected the acquisition of learned responses in Wistar rats (12). Children are more susceptible to radio frequency radiation emissions as their skulls are thinner, their nervous system still developing and myelin sheath is yet not developed (13). The investigation by Salford et al. showed more than half of mammalian brain cell damage after exposure to GSM mobile phone radiations (14). However, there is need to profile the impact of MP radiations to characterize the minutest of changes caused by these non-ionizing radiations on CNS.

Melatonin (MT; N-acetyl-5-methoxy tryptamine), a secretion of pineal gland is known for its antioxidant and free radical scavenging activities (15-19). MT readily crosses the blood-brain barrier (20) and shown to abrogate oxidative stress, through up regulation of important detoxifying enzymes in brain such as, Superoxide dismutase (21), Glutathione peroxidase (22) and also counter lipid peroxidation $(23,24)$. Recent report reveals that $\mathrm{N}^{1}$-acetyl- $\mathrm{N}^{2}-5$-formylmethoxykynuramine and $\mathrm{N}^{1}$-acetyl- $\mathrm{N}^{2}-5$-methoxykynuramine, the two metabolites of MT downregulate the prooxidative and pro-inflammatory enzymes in the CNS (25).

Zebrafish (Danio rerio) have recently emerged as a model organism for CNS studies. The overall organization of the zebrafish brain is similar to other vertebrates (26). As small, resilient vertebrates with mapped and malleable genomes, makes zebrafish a model of choice for to evaluate the genetic and neurophysiologic basis of behavior and cognitive function (27).

This study investigated the impact of 14 days exposure to GSM900 cell phone radiation on the brain oxidative status and the neurobehavioural outcomes in adult zebrafish. Further, the effect of the neurohormone melatonin was explored in this paradigm.

\section{MATERIAL AND METHODS}

Experimental subjects. Adult 120 (3 4 months old) either sex zebrafish (Danio rerio, $\mathrm{AB}$ wild type strain) were used in this study. All the fishes were obtained from a local aquarium store (Kurla market, Mumbai). The fish were kept in $30 \mathrm{~L}$ aquarium tank for 2 weeks in order to acclimatize to the laboratory conditions. The tank water temperature $26 \pm$ $2^{\circ} \mathrm{C}$ and light and dark cycle of $14 / 10 \mathrm{hr}$ were maintained. The fishes were fed twice daily with live tubifex worms or freeze-dried tubifex worms (Red rose aquarium fish food; taiyo pets online trading Pvt. Ltd., Chennai, India).

Exposure protocol. The Nokia X2 handset with SAR$1.34 \mathrm{~W} / \mathrm{Kg}$; service provider-Reliance (900 GSM); were used for exposure purpose. The zebrafish randomized into three groups as control group (no radiation exposure), GSM900MP radiation exposure group and a radiation exposed MT treated group. The experiment was carried out using two rooms, one served for calling (calling room) purpose while the other was used as exposure room. GSM900MP radiation received mobile phone radiations daily $1 \mathrm{hr}$ for 14 days. For this, five zebrafish were placed in glass petridish $3 / 4^{\text {th }}$ filled with home tank water. A piece of paper was place above the glass petridish and mobile handset was kept above the paper. The distance between the zebrafish and the mobile handset was approximately $1.2 \mathrm{~cm}$. Music was played continuously over the line. Other electronic devices that could potentially emit radio frequency radiations were not kept in the exposure room during the exposure period. The stock solution of MT $10 \mu \mathrm{M}$ in water was prepared. For exposure to MT zebrafish $(n=40)$, were exposed to the final MT concentration of $100 \mathrm{nM}$ in $1 \mathrm{~L}$ of water. The MT treated group zebrafish $(n=40)$ were exposed to above concentration of MT daily for $1 \mathrm{hr}$ prior to GSM900MP radiation exposure continued till 14 days. The doses and duration of MT were selected based on study by Zhdanova et al. (28) and pilot experiments in our laboratory. Control zebrafish $(n=40)$ were exposed to same protocol and conditions i.e. kept in beaker containing water devoid of melatonin and placed in petridish but not exposed to mobile phone radiations (for graphical representation see Fig. 1). On day 15, a video camera (Microsoft Lifecam HD) was used to record the neurobehavioral outcomes in all the groups. Subsequently, all zebrafishes were euthanized and brains were dissected out for estimation of oxidative stress parameters. The video analysis was done by using Panlab SMART v3.0 software free version of one month validity (Harvard Apparatus, United States).

\section{Neurobehavioral studies.}

Social interaction test: This test uses 3 compartmental tank (for dimension see Fig. 2). The right compartment and left compartment were designated as social stimulus arm and empty arm, respectively. Along with visual cues, olfactory cues were maintained by setting levels of water in all compartments slightly above the partitions. Individual zebrafish were introduced in the middle compartment. The mid- 


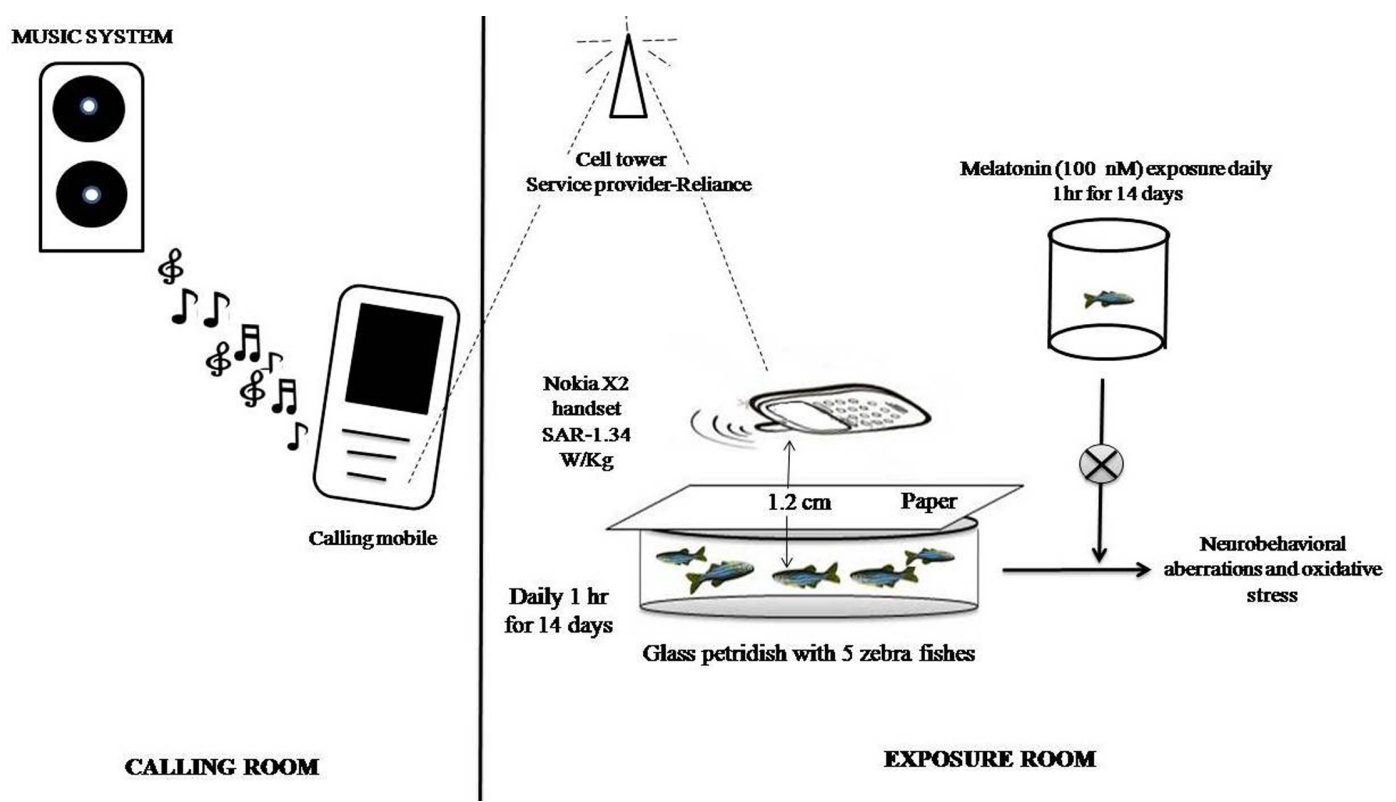

Fig. 1. Graphical representation of exposure setup.

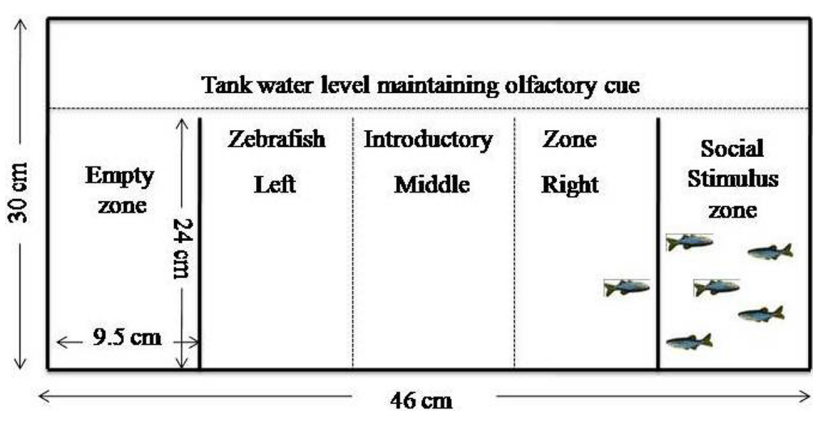

Fig. 2. Schematic representation of social interaction tank design.

dle compartment was virtually divided (no physical barriers) into 3 zones, right, left, and middle. The test runs for $5 \mathrm{~min}$ in which \% time spent in each zone (i.e. near social stimulus, near other arm, in the middle), and total distance travelled was assessed.

Y-Maze test: Y- Maze test was performed as previously reported (29). Briefly, apparatus made with three arms $(25 \mathrm{~cm}$ long, $8 \mathrm{~cm}$ wide and $15 \mathrm{~cm}$ high). Previously established visual cues made of white paper such as squares, triangles and circles were placed on external side of maze walls, so that it can be visible from inside. The maze walls again covered with black plastic self-adhesive film. The apparatus was filled with $3 \mathrm{~L}$ of the home tank water. The three Y-Maze arms were randomized as the start arm, other arm and novel arm. The time spent in each arm was determined. During the first trial (training, $5 \mathrm{~min}$ ), individual zebrafish were allowed to explore only start and other arm with the novel arm closed. For the second trial (test, $5 \mathrm{~min}$ ), the zebrafish were placed back in the same starting arm, with all three arms kept open in order to assess response to novelty.

Novel tank dive test: The open field test is an established paradigm in rodent research, often used to measure exploration and anxiety-related behaviors (30-32). The zebrafish novel tank dive test is used to assess anxiety and locomotion (33-35). On day 15, individual zebrafish from each group was carefully subjected to the novel dive tank test and their movement was tracked for 6 min. The behavioral endpoints like time spent in bottom half, distance travelled, average velocity, number and duration of freezing bouts and number of entries to upper half were used to measure the extent of anxiety $(36,37)$.

\section{Oxidative stress parameters.}

Preparation of brain homogenate: After recording neurobehavioral outcomes, zebrafishes were cryoanaesthetized and euthanized to isolate the brain, washed with icecold saline to remove blood. Brains of ten zebrafishes were pooled in each sample. Each sample was gently homogenized in $50 \mathrm{mM}$ phosphate buffer saline solution of $\mathrm{pH} 7.4$ with homogenizer. The homogenate were centrifuged at $700 \mathrm{rpm}$ for $5 \mathrm{~min}$ at $4^{\circ} \mathrm{C}$ in cooling centrifuge. The resultant pellets were discarded and supernatant were used for estimation of CAT, SOD activities and GSH, LPO levels.

Lipid peroxidation: $100 \mu \mathrm{L}$ of supernatant was mixed $2.5 \mathrm{~mL}$ TBA $(0.7 \%$ in $30 \%$ Glacial acetic acid), incubated at $95^{\circ} \mathrm{C}$ for $1 \mathrm{hr}$. After cooling the mixture was centrifuged at $4000 \mathrm{rpm}$ for $10 \mathrm{~min}$ at $4^{\circ} \mathrm{C}$. The absorbance of the homogenate was read at $532 \mathrm{~nm}$ against the blank. The extent of lipid peroxidation (LPO) was expressed as nmol of malondialdehyde/mg of protein (38). 
Reduced glutathione: Total non-protein sulphydryl content, an indirect measure of reduced GSH, is determined by the method of Sedlak et al., 1968. To $200 \mu \mathrm{L}$ of supernatant, $0.6 \mathrm{~mL}$ of $0.2 \mathrm{mmol} / \mathrm{L}$ Tris-EDTA, $50 \mu \mathrm{L}$ of $0.01 \mathrm{~mol} /$ L 5,5-dithiobis (2-nitrobenzioc acid) i.e. DTNB and $2.5 \mathrm{~mL}$ methanol was added. The mixture was incubated at $37^{\circ} \mathrm{C}$ for $30 \mathrm{~min}$ with occasional shaking. The sample was centrifuged at $4,000 \mathrm{~g}$ for $10 \mathrm{~min}$ at $4^{\circ} \mathrm{C}$. The supernatant separated. The intensity of color developed was determined at $412 \mathrm{~nm}$ against blank treated same way replacing tissue supernatant with distilled water. The amount of reduced glutathione was expressed as $\mu \mathrm{mol}$ of GSH$/ \mathrm{mg}$ protein (39).

Catalase activity: The procedure followed was as discussed previously (40). The reaction mixture consisted of $2 \mathrm{~mL}$ phosphate buffer ( $\mathrm{pH} 7.0$ ), $0.95 \mathrm{~mL}$ of hydrogen peroxide $(0.019 \mathrm{M})$ and $50 \mu \mathrm{L}$ of supernatant in a final volume of $3 \mathrm{~mL}$. Absorbance was recorded at $240 \mathrm{~nm}$ every $10 \mathrm{sec}$ for $1 \mathrm{~min}$. The results were expressed as units of catalase (CAT) activity/mg protein.

Superoxide dismutase activity: The reaction mixture consisted of $0.05 \mathrm{~mL}$ of supernatant, $2 \mathrm{~mL}$ of carbonate buffer and $0.5 \mathrm{~mL}$ of EDTA solution. The reaction was initiated by the addition of $0.5 \mathrm{~mL}$ of epinephrine and the autoxidation of adrenaline to adrenochrome at $\mathrm{pH} 10.2$ was measured by following the change in optical density at $480 \mathrm{~nm}$. Change in optical density every minute was noted at $480 \mathrm{~nm}$ against reagent blank. The results were expressed as units of superoxide dismutase (SOD) activity/mg protein (41).
Statistical analysis: All values are expressed as mean \pm SEM $(n=40)$. Statistical analyses were performed using GraphPad Prism 5 software for Windows (GraphPad Software, San Diego, CA, USA). The differences between the groups were analyzed with one-way analysis of variance, followed by post hoc analysis with Newmen-Keuls test. Statistical significance was considered at $p<0.05$.

\section{RESULTS}

\section{Impact of GSM900 mobile phone radiation on neuro- behavioral outcomes.}

Social interaction test: Social interaction test is a useful model to study fish social phenotypes (37). In present study, control group zebrafish spent their entire time in right zone (social stimulus side), in contrast GSM900MP radiation exposed group zebrafish spent $22.00 \%, 35.29 \%$ and $42.51 \%$ time in left, middle and right zone, respectively and shown increased total distance travelled compared to control zebrafish. MT treated zebrafish spent 71.68\%, 15.45\% and $8.77 \%$ time in left, middle and right zone, respectively signifying restoration of the social stimulus but no significant difference was seen in total distance travelled (Fig. 4). For representative tracings see Fig. 3(A, B, and C).

Novel tank dive test: In 6 min novel tank dive test, GSM900MP radiation exposure in zebrafish produced increase in time spent in bottom half $\left[\mathrm{F}_{2,119}=108.9, p<\right.$ $.0001]$, freezing bouts $\left[\mathrm{F}_{2,119}=38.47, p<.0001\right]$ and freez-

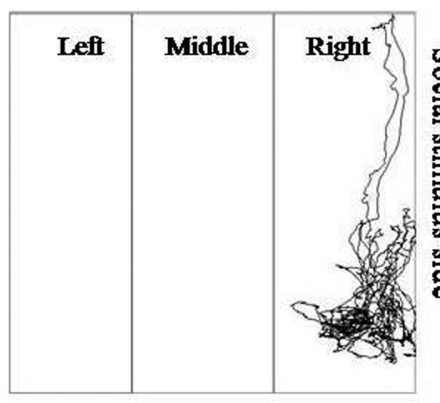

(A) Control zebrafish

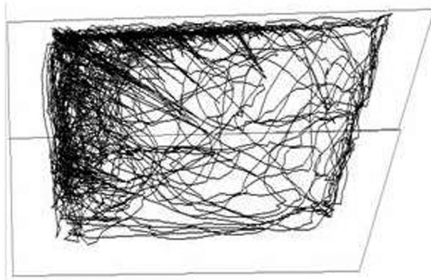

(D) Control zebrafish

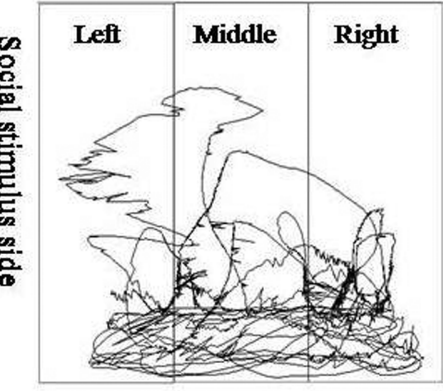

(B) Mobilephoneradiation exposedzebrafish

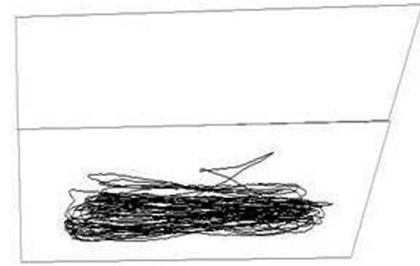

(E) Mobilephoneradiation exposedzebrafish

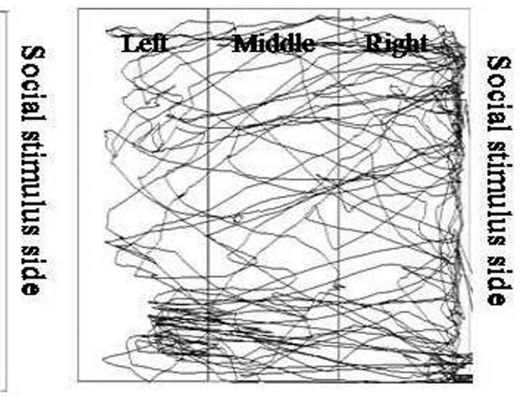

(C) MT treated zebrafish

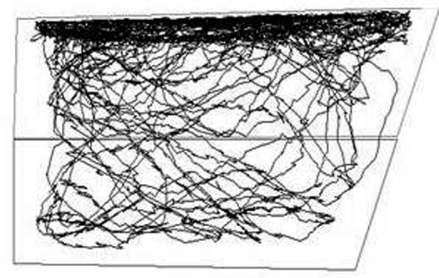

(F) MT treated zebrafish

Fig. 3. Representative tracings of zebrafish in social interaction test and novel tank dive test. (A), (B) and (C) shows social interaction test tracings for Control (non-exposed), GSM900MP radiation exposed and MT treated zebrafish, respectively; (D), (E) and (F) were novel tank dive test tracings for Control (non-exposed), GSM900MP radiation exposed and MT treated zebrafish, respectively. 
(A)

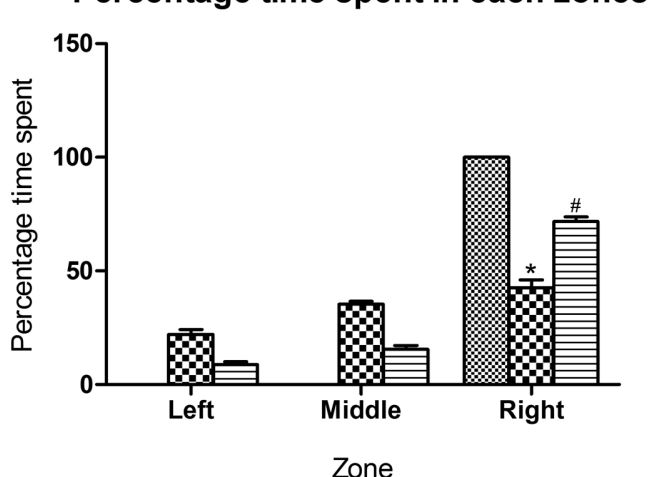

(B)

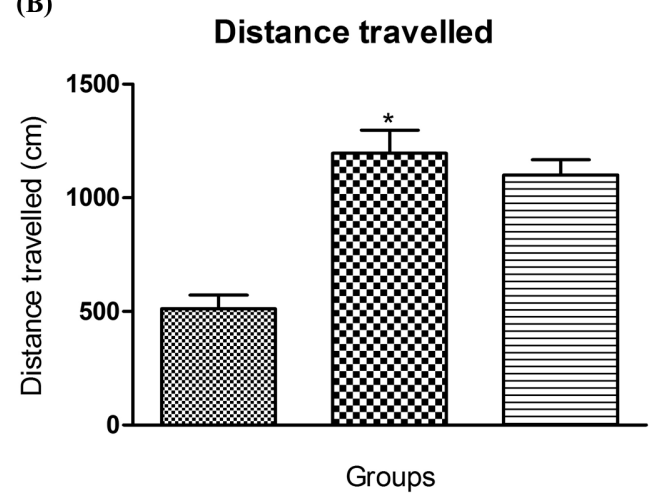

MT treated

Fig. 4. Effect of GSM900MP radiation exposure on time spent in each zone and total distance travelled in social interaction test. The data is represented as the mean \pm SEM $(n=40)$. The data is represented as the mean \pm SEM $(n=40)$. Statistical analysis was performed by using one-way analysis of variance (ANOVA), followed by Newmen-Keuls test as a post-hoc analysis to identify significant differences among the groups. MT, Melatonin. ${ }^{*} p<0.05$ versus control and ${ }^{\#} p<0.05$ versus radiation exposed group.

ing duration $\left[\mathrm{F}_{2,119}=46.20, p<.0001\right]$, and decreased total distance travelled $\left[\mathrm{F}_{2,119}=53.09, p<.0001\right]$, average velocity $\left[\mathrm{F}_{2,119}=10.22, p<.0001\right]$, and number of entries to upper half $\left[\mathrm{F}_{2,119}=18.35, p<.0001\right]$, as compared to that of control zebrafish without GSM900MP radiation exposure. MT treatment showed significant anxiolytic activity by reversing these outcomes in this test (Fig. 5A-F), as reflected in their representative tracings in Fig. 3(D, E and F).

Y-Maze test: In Y-Maze test, the control zebrafishes spent significantly more percentage of time $(69.2 \%)$ in exploring novel arm, as compared to start $(16.3 \%)$ and other arm (14.5\%). While novel arm exploration were significantly altered in GSM900MP radiation exposed zebrafishes $(32.3 \%)$ as compared to non-exposed control zebrafishes. MT treatment significantly counters the GSM900MP radiation induced alteration on learning by improving the novel arm exploration (70.1\%) (Fig. 6)

Impact of GSM900MP radiation on oxidative stress parameters in zebrafish brain: Fig. 7 represents the changes in antioxidant parameters in zebrafish brains. The malondialdehyde levels, an indicator of lipid peroxidation (LPO) were increased in the GSM900MP radiation exposed zebrafish brain $(2.21 \mathrm{nmol} / \mathrm{mg}$ protein versus non exposed zebrafishes $0.91 \mathrm{nmol} / \mathrm{mg}$ protein). MT treatment abated this dramatic increase $(1.01 \mathrm{nmol} / \mathrm{mg}$ protein) showing prompt antioxidant potential.

Reduced glutathione (GSH) protects the cells from free radicals and oxidative insults. In current study, GSH levels upon GSM900MP radiation exposure were significantly increased to $22.22 \mu \mathrm{mol} / \mathrm{mg}$ protein in contrast to levels of non exposed group i.e. $12.45 \mu \mathrm{mol} / \mathrm{mg}$ protein. MT treatment maintained GSH levels $(15.20 \mu \mathrm{mol} / \mathrm{mg}$ protein $)$.

The SOD, dismutase's $\mathrm{O}_{2}$ anions, decrease in its activity directly relates augmentation in oxidative stress. The decrease in its activity in the GSM900MP radiation exposed zebrafish (15.22 units/mg protein) as compared to the non exposed group ( 25.23 units/mg protein) bears the testimony to the oxidative stress inducing effects of these radiations. MT treatment prevented this decrease showing its promising antioxidant potential (23.00 units/mg protein).

Catalase scavenges the hydrogen peroxide and decreases its levels. Catalase activity of 3.5 units $/ \mathrm{mg}$ protein was seen in non exposed zebrafish brains. The exposure of GSM900MP radiation for 14 days led to a significant drop in catalase activity to 1.2 units/mg protein which was restored upon MT treatment (3.1 units/mg protein).

\section{DISCUSSION}

Currently, across the globe, there are over 3 billion cell phone users and the count is ever increasing (42). The cell phone consumer market is fast expanding with time, proportionately, increasing adversity to the human health (43-45). In order to shield against the possible detrimental effects of these microwaves/radio frequency waves in humans, it is imperative that stricter radiation norms must be enforced by the policy makers and more elaborate research should thoroughly profile its impact. The impact of cell phone radiations on zebrafish hasn't been explored in the past. Zebrafish was deemed to be a species to carry out the exploratory studies to substantiate the impact of mobile phone radiations (46). In the current investigation we exposed the zebrafish to non ionizing radiations using Nokia X2 mobile handset with SAR-1.34 W/Kg and the service provider was Reliance (900 GSM), daily for $1 \mathrm{hr}$ for 14 days to assess its effect on neurobehavioral and brain oxidative stress parameters.

Zebrafish exhibit many social characteristics like recog- 
(A)
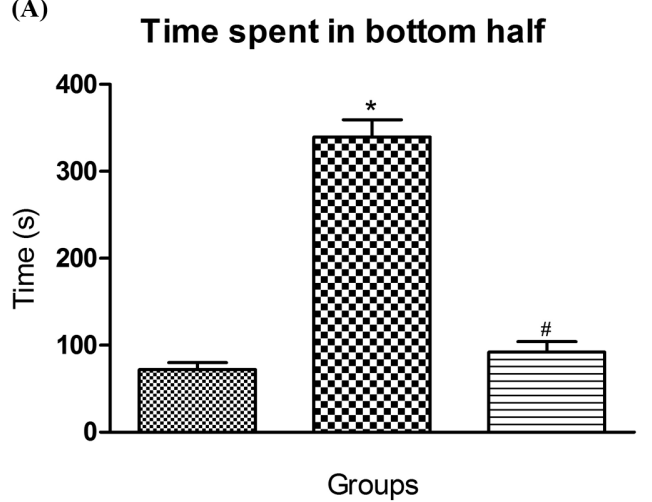

(C)

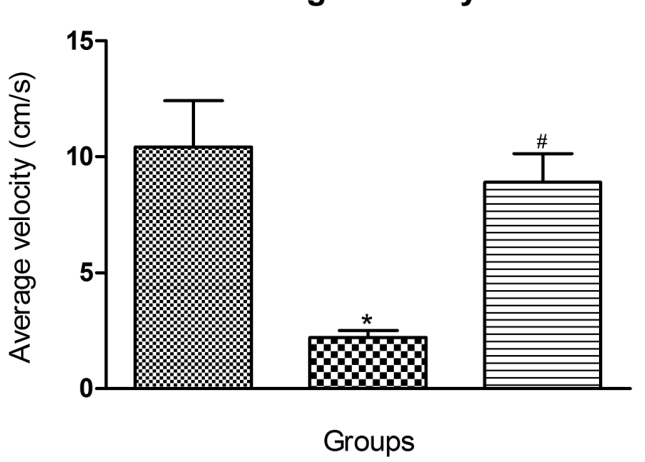

(E)

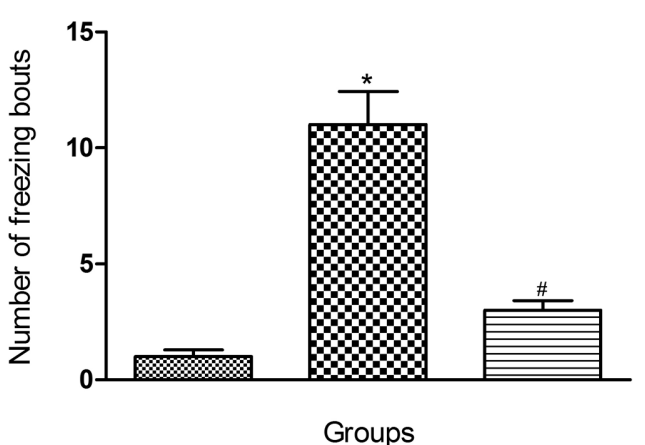

Groups
(B)

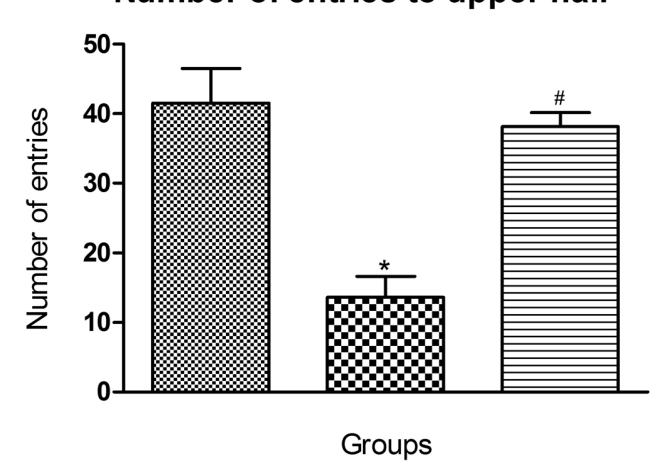

(D)

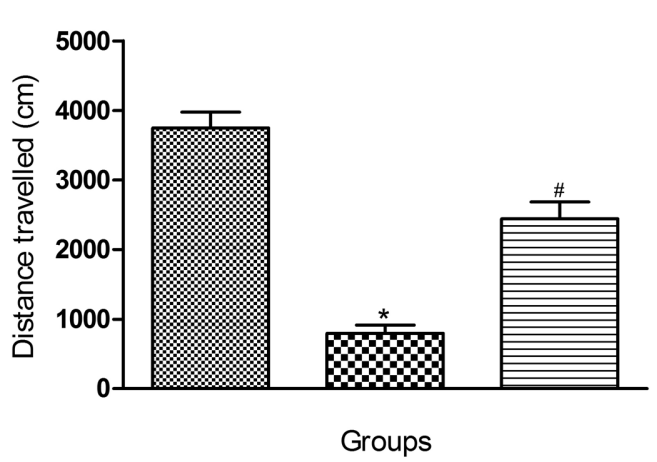

(F)

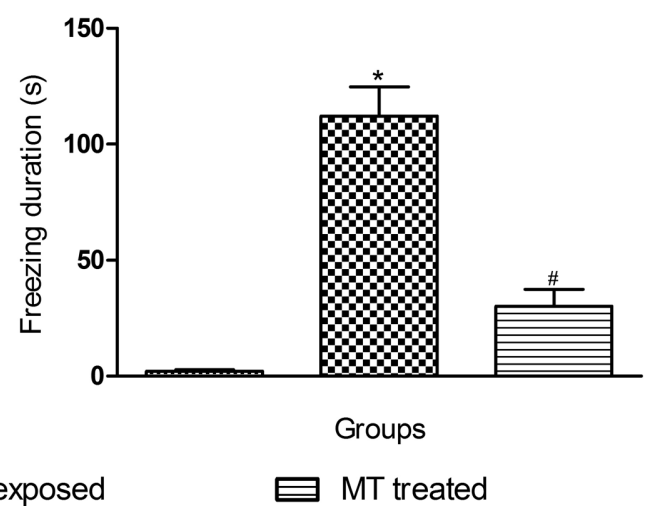

Fig. 5. Effect of GSM900MP radiation exposure on time spent in bottom half, number of entries to upper half, average velocity, total distance travelled, average duration and number of freezing bouts, in novel tank dive test. The data is represented as the mean \pm SEM $(n=40)$. Statistical analysis was performed by using one-way analysis of variance (ANOVA), followed by Newmen-Keuls test as a posthoc analysis to identify significant differences among the groups. MT, Melatonin. ${ }^{*} p<0.05$ versus control and ${ }^{\#} p<0.05$ versus radiation exposed group.

nizing each other by sight and odor, social learning phenomenon, aggressive behavior, spatial navigation skills as well as cognitive and adaptative behavior such as habituation making them a model system to study behavioral pharmacology $(47,48)$. The social preference test discriminates whether there is interest for the social stimulus or not (37). Our results has revealed that, GSM900MP radiation exposure in zebrafish significantly decreases exploration near social stimulus zone with increased total distance travelled as compared to that of non-exposed zebrafish.

Zebrafish have emerged as a promising model for anxiety research $(33,49-53)$. Different paradigms have been used to evaluate anxiety in zebrafish; amongst them the novel tank dive test mainly assesses geotaxic vertical behavior (54). A previous study by Daniels et al., demonstrated reduction in locomotor activity, increased grooming and 


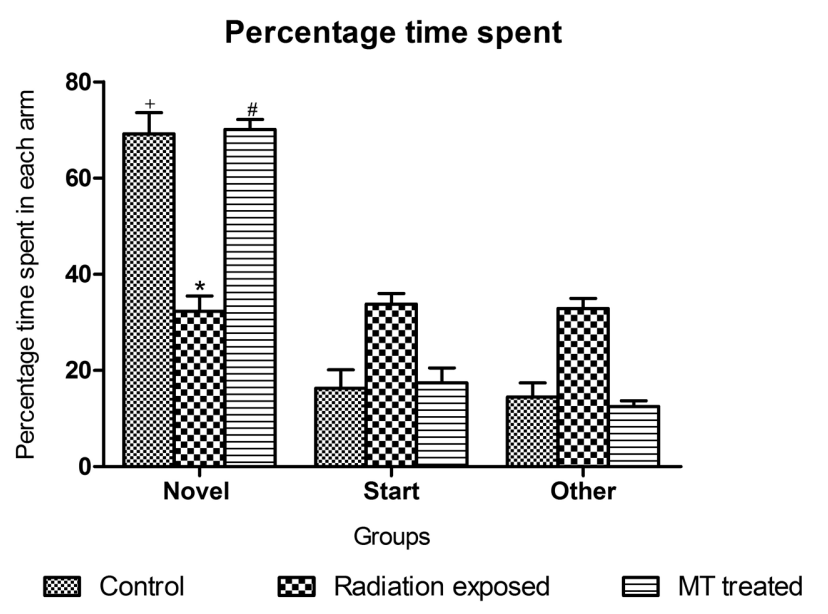

Fig. 6. Effect of GSM900MP radiation exposure on percentage time spent in each arm of Y-Maze. The data is represented as the mean \pm SEM $(n=40)$. Statistical analysis was performed by using one-way analysis of variance (ANOVA), followed by Newmen-Keuls test as a post-hoc analysis to identify significant differences among the groups. MT, Melatonin. ${ }^{*} p<0.05$ versus control novel arm; ${ }^{+} p<0.05$ versus start and other arm and $\# p<0.05$ versus radiation exposed novel arm.

(A)

\section{LPO}

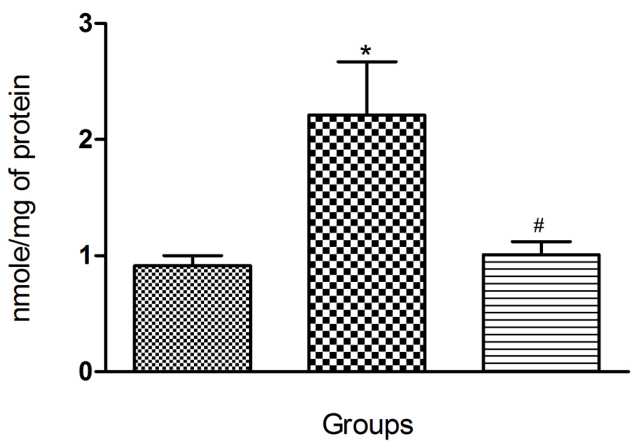

(C)

CAT

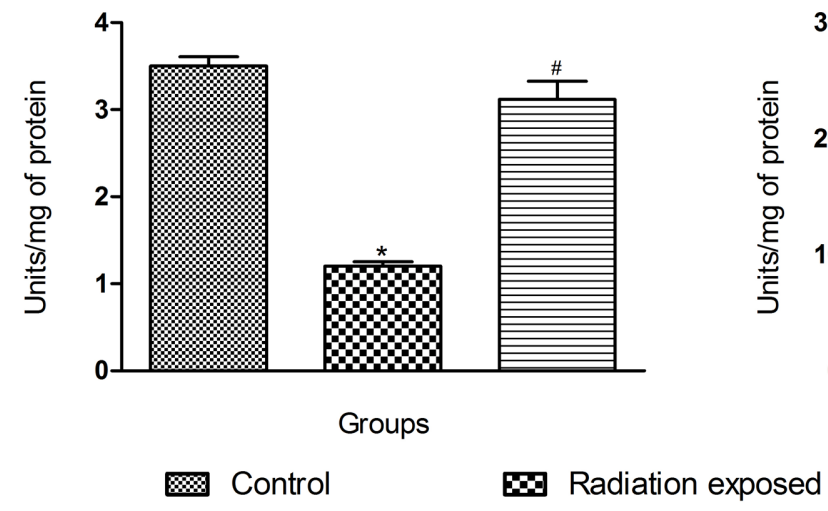

freezing behavior in rats upon EMR exposure in the mobile phone range (55). While in another study, Sokolovic et al., reported microwave radiation from mobile phone produced anxiety related behavior in animals (56). Similarly, our study on zebrafish has shown typical induction of anxious behavior on exposure to GSM900MP radiation. This was evaluated using the novel tank dive test, duly reflecting increase in time spent in bottom half, freezing bouts and duration, decreased distance travelled, reduced average velocity and number of entries to upper half of the tank.

Several studies in the past have shown significant impairment in learning and memory due to mobile phone radiation exposure (57-59). The Y-maze test is important tool to evaluate the cognition since it offers a model which lacks conditioned learning, emotional and motivational influence, and taps the natural tendency of the fishes to novel arenas (29). In the present investigation, GSM900MP radiation significantly altered the curiosity driven exploration of novel arm in the Y-maze arena as compared to that of control zebrafish, showing significant impairment in learning and memory.

The reactive oxygen species (ROS) are the main culprit

(B)

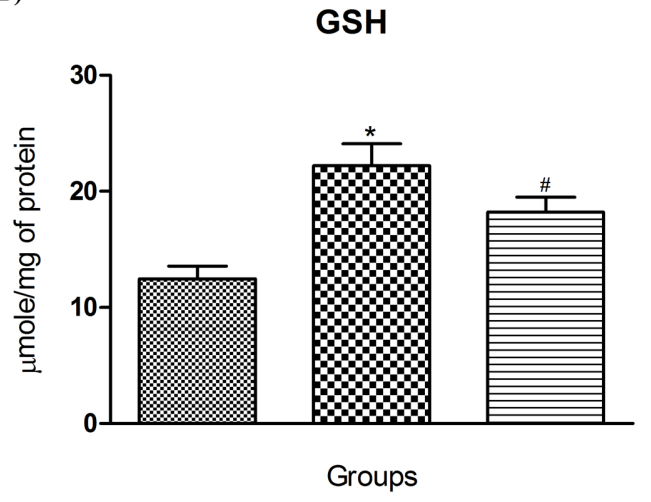

(D)
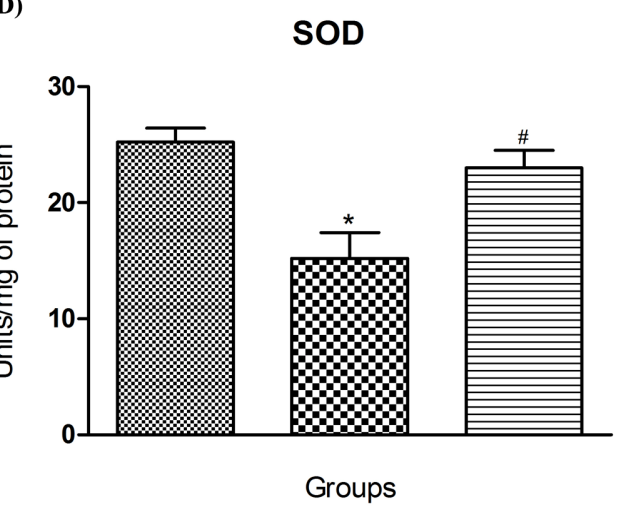

MT treated

Fig. 7. Effect of GSM900MP radiation on brain oxidative stress parameters. The data is represented as the mean \pm SEM of four samples from each group, each one performed in duplicate. Statistical analysis was performed by using one-way analysis of variance (ANOVA), followed by Newmen-Keuls test as a post-hoc analysis to identify significant differences among the groups. MT, Melatonin. ${ }^{*} p<0.05$ versus control and ${ }^{\#} p<0.05$ versus radiation exposed group. 
for development of oxidative stress (60). The antioxidant enzymes (SOD and CAT) and the thiol (GSH) scavenge the free radicals in brain, acting as cellular antioxidants. Assessment of these cellular antioxidants helps in monitoring oxidative stress (61). The exposure of $900 \mathrm{MHz}$ and 50 GHz microwave radiations causes decrease in SOD, glutathione peroxidase (GPx) and increase in CAT activity in rat brain (3). The current study reveals decrease in SOD, CAT activities with an increase in LPO and GSH levels on GSM900MP radiation exposure. The increase in GSH levels may be attributed to an adaptive response to ROS production (62). In addition, toxicants that induce oxidative stress is known to lead to increased GSH levels in rats and cultured rat CNS cells $(63,64)$.

The study confirmed that, MT treatment comprehensively counters the brain oxidative stress by restoring activities of SOD and CAT and maintaining the levels of GSH and LPO in zebrafish. This effect was amenable to the reports that its metabolites acts as endogenous buffering agents $(25,65)$. This neurohormone is an important modulator of central nervous system. The investigation revealed that, MT treated zebrafish showed significant abatement in GSM900MP radiation induced anxiety, alteration in social preference and learning as concluded from the results of novel tank dive test, social interaction test and Y-Maze test, respectively.

Thus, the study helped us to unearth the impact of acute GSM900MP radiation exposure associated detrimental outcomes on neurobehavioral and brain antioxidant parameters, in adult zebrafish. In summary, this was a pragmatic attempt to profile the impact of the mobile phone non-ionizing radiations in zebrafish. The data may be extrapolated to the changes that might be induced due to non-ionizing radiation exposure in humans. Moreover, evidences were generated proving the potential of melatonin in abating these induced changes to shed light on a possible putative therapy. However, more elaborate research duly addressing cellular and molecular changes will be needed to evaluate the effects of non ionizing radiations on human and animal health.

\section{REFRENCES}

1. Sivani, S. and Sudarsanam, D. (2012) Impacts of radio-frequency electromagnetic field (RF-EMF) from cell phone towers and wireless devices on biosystems and ecosystem - a review. Bio. Med., 4, 202-216.

2. Kumar, N. and Kumar, G. (2009) Biological effects of cell tower radiation on human body, ISMOT, New Delhi, pp. 1365-1368.

3. Kesari, K.K., Siddiqui, M.H., Meena, R., Verma, H.N. and Kumar, S. (2013) Cell phone radiation exposure on brain and associated biological systems. Indian J. Exp. Biol., 15, 187200.

4. Valberg, P.A., van Deventer, T.E. and Repacholi, M.H. (2007) Workgroup report: Base stations and wireless networks:
Radiofrequency (RF) exposures and health consequences. Environ. Health Perspect., 115, 416-424.

5. Repacholi, M.H. (2001) Health risks from the use of mobile phones. Toxicol. Lett., 120, 323-331.

6. Hamada, A.J., Singh, A. and Agarwal, A. (2011) Cell phones and their impact on male fertility: fact or fiction. Open Reprod. Sci. J., 5, 125-137.

7. Hardell, L., Carlberg, M. and Hansson Mild, K. (2009) Epidemiological evidence for an association between use of wireless phones and tumor diseases. Pathophysiology, 16,113-122.

8. Leszczynski, D., Joenväärä, S., Reivinen, J. and Kuokka, R. (2002) Non-thermal activation of the hsp27/p38MAPK stress pathway by mobile phone radiation in human endothelial cells: molecular mechanism for cancer- and blood-brain barrier related effects. Differentiation, 70, 120-129.

9. World Health Organization (2007) Neurodegenerative disorders in environmental health criteria. p. 187.

10. Wilmink, G.J. and Grundt, J.E. (2011) Invited Review Article: Current state of research on biological effects of terahertz radiation. J. Infrared Millim. Terahertz Waves, 32, 1074-1122.

11. Nittby, H., Grafström, G., Tian, D., Malmgren, L., Brun, A., Persson, B.R., Salford, L.G. and Eberhardt, J. (2008) Cognitive impairment in rats after long-term exposure to GSM-900 mobile phone radiation. Bioelectromagnetics, 29, 219-232.

12. Narayanan, S.N., Kumar, R.S., Potu, B.K., Nayak, S. and Mailankot, M. (2009) Spatial memory performance of Wistar rats exposed to mobile phone. Clinics (Sao Paulo), 64, 231234.

13. Frey, A.H. (1988) Evolution and results of biological research with low-intensity non-ionizing radiation in modern bioelectricity (Marino, A.A. Ed.). Dekker, New York, pp. 785-837.

14. Salford, L.G., Brun, A., Eberhardt, J.L., Malmgren, L. and Persson, B.R. (2003) Nerve cell damage in mammalian brain after exposure to microwaves from GSM mobile phones. Environ. Health Perspect., 111, 881-883.

15. Baydas, G., Reiter, R.J., Nedzvetskii, V.S., Yaşar, A., Tuzcu, M., Ozveren, F. and Canatan, H. (2003) Melatonin protects the central nervous system of rats against toluene-containing thinner intoxication by reducing reactive gliosis. Toxicol. Lett., 137, 169-174.

16. Rodriguez, C., Mayo, J.C., Sainz, R.M., Antolín, I., Herrera, F., Martín, V. and Reiter, R.J. (2004) Regulation of antioxidant enzymes: a significant role for melatonin. J. Pineal Res., 36, 1-9.

17. Baydas, G., Ozveren, F., Akdemir, I., Tuzcu, M. and Yasar, A. (2005) Learning and memory deficits in rats induced by chronic thinner exposure are reversed by melatonin. J. Pineal Res., 39, 50-56.

18. Gitto, E., Pellegrino, S., Gitto, P., Barberi, I. and Reiter, R.J. (2009) Oxidative stress of the newborn in the pre- and postnatal period and the clinical utility of melatonin. J. Pineal Res., 46, 128-139.

19. Korkmaz, A., Reiter, R.J., Topal, T., Manchester, L.C., Oter, S. and Tan, D.X. (2009) Melatonin: an established antioxidant worthy of use in clinical trials. Mol. Med., 15, 43-50.

20. Menendez-Pelaez, A., Poeggeler, B., Reiter, R.J., BarlowWalden, L., Pablos, M.I. and Tan, D.X. (1993) Nuclear localization of melatonin in different mammalian tissues: immunocytochemical and radioimmunoassay evidence. J. Cell. Biochem., 
53, 373-382.

21. Antolín, I., Rodríguez, C., Saínz, R.M., Mayo, J.C., Uría, H., Kotler, M.L., Rodríguez-Colunga, M.J., Tolivia, D. and Menéndez-Peláez, A. (1996) Neurohormone melatonin prevents cell damage: effect on gene expression for antioxidant enzymes. FASEB J., 10, 882-890.

22. Barlow-Walden, L.R., Reiter, R.J., Abe, M., Pablos, M., Menendez-Pelaez, A., Chen, L.D. and Poeggeler, B. (1995) Melatonin stimulates brain glutathione peroxidase activity. Neurochem. Int., 26, 497-502.

23. Melchiorri, D., Reiter, R.J., Attia, A.M., Hara, M., Burgos, A. and Nistico, G. (1995) Potent protective effect of melatonin on in vivo paraquat-induced oxidative damage in rats. Life Sci., 56, 83-89.

24. Reiter, R., Tang, L., Garcia, J.J. and Muñoz-Hoyos, A. (1997) Pharmacological actions of melatonin in oxygen radical pathophysiology. Life Sci., 60, 2255-2271.

25. Hardeland, R., Tan, D.X. and Reiter, R.J. (2009) Kynuramines, metabolites of melatonin and other indoles: the resurrection of an almost forgotten class of biogenic amines. $J$. Pineal Res., 47, 109-126.

26. Lamb, E.A., Echevarria, D.J. and Jouandot, D.J. (2012) The utility of the T-maze in assessing learning, memory and models of neurological disorders in the zebrafish. Behaviour, 149, 1081-1097.

27. Guo, S. (2004) Linking genes to brain, behavior, and neurological diseases: What can we learn from zebrafish? Genes Brain Behav., 3, 63-74.

28. Zhdanova, I.V., Yu, L., Lopez-Patino, M., Shang, E., Kishi, S. and Guelin, E. (2008) Aging of the circadian system in zebrafish and the effects of melatonin on sleep and cognitive performance. Brain Res. Bull., 75, 433-441.

29. Cognato, G.P., Bortolotto, J.W., Blazina, A.R., Christoff, R.R., Lara, D.R., Vianna, M.R. and Bonan, C.D. (2012) Y-Maze memory task in zebrafish (Danio rerio): The role of glutamatergic and cholinergic systems on the acquisition and consolidation periods. Neurobiol. Learn. Mem., 98, 321-328.

30. Hall, C.S. (1934) Emotional behavior in the rat. I. Defecation and urination as measures of individual differences in emotionality. J. Com. Psychol., 18, 385-403.

31. Christmas, A.J. and Maxwell, D.R. (1970) A comparison of the effects of some benzodiazepines and other drugs on aggressive and exploratory behaviour in mice and rats. Neuropharmacology, 9, 17-29.

32. Prut, L. and Belzung, C. (2003) The open field as a paradigm to measure the effects of drugs on anxiety-like behaviors: a review. Eur. J. Pharmacol., 463, 3-33.

33. Egan, R.J., Bergner, C.L., Hart, P.C., Cachat, J.M., Canavello, P.R., Elegante, M.F., Elkhayat, S.I., Bartels, B.K., Tien, A.K., Tien, D.H., Mohnot, S., Beeson, E., Glasgow, E., Amri, H., Zukowska, Z. and Kalueff, A.V. (2009) Understanding behavioral and physiological phenotypes of stress and anxiety in zebrafish. Behav. Brain Res., 205, 38-44.

34. Levin, E.D., Bencan, Z. and Cerutti, D.T. (2007) Anxiolytic effects of nicotine in zebrafish. Physiol. Behav., 90, 54-58.

35. Bencan, Z., Sledge, D. and Levin, E.D. (2009) Buspirone, chlordiazepoxide and diazepam effects in a zebrafish model of anxiety. Pharmacol. Biochem. Behav., 94, 75-80.

36. Stewart, A., Cachat, J., Wong, K., Gaikwad, S., Gilder, T.,
DiLeo, J., Chang, K., Utterback, E. and Kalueff, A.V. (2010) Homebase behavior of zebrafish in novelty-based paradigms. Behav. Processes, 85, 198-203.

37. Grossman, L., Utterback, E., Stewart, A., Gaikwad, S., Chung, K.M., Suciu, C., Wong, K., Elegante, M., Elkhayat, S., Tan, J., Gilder, T., Wu, N., Dileo, J., Cachat, J. and Kalueff, A.V. (2010) Charactrisation of behavioural and endocrine effects of LSD on zebrafish. Behav. Brain Res., 214, 277-84.

38. Ohkawa, H., Ohishi, N. and Yagi, K. (1979) Assay for lipid peroxides in animal tissues by thiobarbituric acid reaction. Anal. Biochem., 95, 351-358.

39. Sedlak, J. and Lindsay, R.H. (1968) Estimation of total, protein-bound, and nonprotein sulfhydryl groups in tissue with Ellman's reagent. Anal. Biochem., 25, 192-205.

40. Beers, R.F. Jr. and Sizer, I.W. (1952) A spectrophotometric method for measuring the breakdown of hydrogen peroxide by catalase. J. Biol. Chem., 195, 133-140.

41. Sun, M. and Zigman, S. (1978) An improved spectrophotometric assay for superoxide dismutase based on epinephrine autoxidation. Anal. Biochem., 90, 81-89.

42. International Telecommunications Union (2010) The world in 2010: ICT facts and figures. Available from: http://www.itu.int/ ITU-D/ict/material/FactsFigures2010.pdf.

43. Kesari, K.K., Kumar, S. and Behari, J. (2010) Mobile phone usage and male infertility in Wistar rats. Indian J. Exp. Biol., 48, 987-992.

44. Dasdag, S., Akdag, M.Z., Kizil, G., Kizil, M., Cakir, D.U. and Yokus, B. (2012) Effect of $900 \mathrm{MHz}$ radio frequency radiation on beta amyloid protein, protein carbonyl, and malondialdehyde in the brain. Electromagn. Biol. Med., 31, 67-74.

45. Finnie, J.W., Cai, Z., Manavis, J., Helps, S. and Blumbergs, P.C. (2010) Microglial activation as a measure of stress in mouse brains exposed acutely (60 minutes) and long-term (2 years) to mobile telephone radiofrequency fields. Pathology, 42, 151-154.

46. Collier, A.D. and Echevarria, D.J. (2013) The utility of the zebrafish model in conditioned place preference to assess the rewarding effects of drugs. Behav. Pharmacol., 24, 375-383.

47. Iturriaga-Vásquez, P., Osorio, F., Riquelme, S., Catro, S. and Herzog, R. (2012) Zebrafish: A model for behavioural pharmacology. Rev. Farmacol. Chile, 5, 27-32.

48. Oliveira, R.F. (2013) Mind the fish: zebrafish as a model in cognitive social neuroscience. Front. Neural Circuits, 7, 131.

49. Bencan, Z. and Levin, E.D. (2008) The role of $\alpha 7$ and $\alpha 4 \beta 2$ nicotinic receptors in the nicotine-induced anxiolytic effect in zebrafish. Physiol. Behav., 95, 408-412.

50. Braida, D., Limonta, V., Pegorini, S., Zani, A., Guerini-Rocco, C., Gori, E. and Sala, M. (2007) Hallucinatory and rewarding effect of salvinorin $\mathrm{A}$ in zebrafish: $\kappa$-opioid and $\mathrm{CB}_{1}$-cannabinoid receptor involvement. Psychopharmacology, 190, 441448.

51. López Patiño, M.A., Yu, L., Yamamoto, B.K. and Zhdanova, I.V. (2008) Gender differences in zebrafish responses to cocaine withdrawal. Physiol. Behav., 95, 36-47.

52. Bass, S.L. and Gerlai, R. (2008) Zebrafish (Danio rerio) responds differentially to stimulus fish: the effects of sympatric and allopatric predators and harmless fish. Behav. Brain Res., 186, 107-117.

53. Speedie, N. and Gerlai, R. (2008) Alarm substance induced 
behavioral responses in zebrafish (Danio rerio). Behav. Brain Res., 188, 168-177.

54. Stewart, A., Gaikwad, S., Kyzar, E., Green, J., Roth, A. and Kalueff, A. (2012) Modeling anxiety using adult zebrafish: A conceptual review. Neuropharmacology, 62, 135-143.

55. Daniels, W.M., Pitout, I.L., Afullo, T.J. and Mabandla, M.V. (2009) The effect of electromagnetic radiation in the mobile phone range on the behaviour of the rat. Metab. Brain Dis., 24, 629-641.

56. Sokolovic, D., Djordjevic, B., Kocic, G., Babovic, P., Ristic, G., Stanojkovic, Z., Sokolovic, D.M., Veljkovic, A., Jankovic, A. and Radovanovic, Z. (2012) The effect of melatonin on body mass and behaviour of rats during an exposure to microwave radiation from mobile phone. Bratisl. Lek. Listy., 113, 265-269.

57. Haarala, C., Takio, F., Rintee, T., Laine, M., Koivisto, M., Revonsuo, A. and Hämäläinen, H. (2007) Pulsed and continuous wave mobile phone exposure over left versus right hemisphere: effects on human cognitive function. Bioelectromagnetics, 28, 289-295.

58. Kwon, M.S., Koivisto, M., Laine, M. and Hämäläinen, H. (2008) Perception of the electromagnetic field emitted by a mobile phone. Bioelectromagnetics, 29, 154-159.

59. Ntzouni, M.P., Stamatakis, A., Stylianopoulou, F. and Margaritis, L.H. (2011) Short-term memory in mice is affected by mobile phone radiation. Pathophysiology, 18, 193-199.

60. Schrader, S.M. and Kanitz, M.H. (1994) Occupational hazards to male reproduction in occupational medicine: State of the art reviews. (Gold, E., Schenker, M. and Lasley, B. Ed.). Hanley and Belfus, Philadelphia, pp. 405-414.

61. Rahman, K. (2007) Studies on free radicals, antioxidants, and co-factors. Clin. Interv. Aging, 2, 219-236.

62. Lillig, C.H., Berndt, C. and Holmgren, A. (2008) Glutaredoxin systems. Biochim. Biophys. Acta, 1780, 1304-1317.

63. Conterato, G.M., Augusti, P.R., Somacal, S., Einsfeld, L., Sobieski, R., Torres, J.R. and Emaneulli, T. (2007) Effect of lead acetate on cytosolic thioredoxin reductase activity and oxidative stress parameters in rat kidneys. Basic Clin. Pharmacol. Toxicol., 101, 96-100.

64. Narayanan, P.K., Carter, W.O., Ganey, P.E., Roth, R.A., Voytik-Harbin, S.L. and Robinson, J.P. (1998) Impairment of human neutrophil oxidative burst by polychlorinated biphenyls: inhibition of superoxide dismutase activity. J. Leukoc. Biol., 63, 216-224.

65. Manda, K., Ueno, M. and Anzai, K. (2008) Space radiationinduced inhibition of neurogenesis in the hippocampal dentate gyrus and memory impairment in mice: ameliorative potential of the melatonin metabolite, AFMK. J. Pineal Res., 45, 430-438. 